\title{
HYBRIDIZATION THRU A RANGE EXTENDER ENGINE
}

\author{
Marcos Clemente ${ }^{1}$, Simon Reader ${ }^{2}$ and Dr. Martin Berger ${ }^{3}$ \\ ${ }^{1}$ MAHLE Powertrain Brazil, Rodovia Anhanguera, sentido interior - capital, Jundiaí, Brasil \\ ${ }^{2}$ MAHLE Powertrain Ltd., Costin House, St. James Mill Road, Northampton, NN5 5TZ, UK \\ ${ }^{3}$ MAHLE Powertrain GmbH, Schaflandstr. 10/1, 70736 Fellbach, Germany \\ E-mails: marcos.clemente@br.mahle.com, simon.reader@gb.mahle.com, \\ martin.berger@mahle.com
}

\begin{abstract}
Current focus on techniques to reduce the tailpipe carbon dioxide $\left(\mathrm{CO}_{2}\right)$ emissions of road vehicles is increasing the interest in hybrid and electric vehicle technologies. Pure electric vehicles require bulky, heavy, and expensive battery packs to enable an acceptable driving range. Range Extended Electric Vehicles (REEVs) partly overcome the limitations of current battery technology by having a range extender (REx) unit that allows a reduction of the traction battery storage capacity, whilst still maintaining an acceptable vehicle driving range.

MAHLE have developed a family of range extender (REx) units specifically for passenger car applications. Key attributes for the engine were identified as being minimum package volume, low weight, low cost, and good noise, vibration and harshness (NVH) performance. In order to showcase the resulting REx unit a current production gasoline fuelled compactclass car has been converted into a REEV. The integration of REx, along with considerations for the operating strategy, including a GPS based strategy, and results showing the measured fuel efficiency are presented.
\end{abstract}

\section{INTRODUCTION}

Because electric vehicles (EVs) do not generate pollutants during usage, and they can potentially rely on energy provided by a selection of renewable sources, they are the focus of much current interest. However, due to the present capabilities of battery cell technology, the overall range of such vehicles is limited in comparison to an equivalent conventionally fuelled vehicle. Furthermore, once the battery is depleted, relatively long recharging times are currently required before the vehicle is ready to be re-used.

Plug-in hybrid electric vehicles (PHEVs), of which REEVs are a subset, overcome many of the short-comings of pure EVs. REEVs have a 'range extender' unit, which consists of an onboard fuel converter that converts a liquid fuel, such as gasoline, into electrical energy whilst the vehicle is driving. This enables the traction battery storage capacity to be reduced, though still maintaining an acceptable vehicle driving range. For long journeys, when the battery and 
fuel tank are both depleted, the driver can simply refuel the gasoline tank in a matter of minutes using the existing refueling infrastructure.

However, it is desirable that for the majority of the time that the vehicle will operate in a purely electric mode, from the battery, and that the user recharges the vehicle when it is not in use (e.g. over-night). Thus, the battery should be sized to cope with the majority of daily usage that the vehicle will encounter, and only rely on the range extender for longer, less frequent, journeys.

A dedicated REx engine, as shown in Figure 1, has been developed to identify the requirements and challenges faced in the development of the components for such future engines. This REx engine has been designed specifically to meet the requirements for a compact-class REEV. During the concept phase of the project key attributes for the engine were identified and a full evaluation of the different possible layouts for the REx engine was undertaken to assess the most suitable for the intended application.

In order to enable development and refinement of the REx system, it has been installed into a vehicle. A current production vehicle has been fitted with an electric drive-line and the range extender engine. The REEV specification has been developed with the target of matching the dynamic performance of the conventional baseline vehicle up to typical motorway cruising speeds.

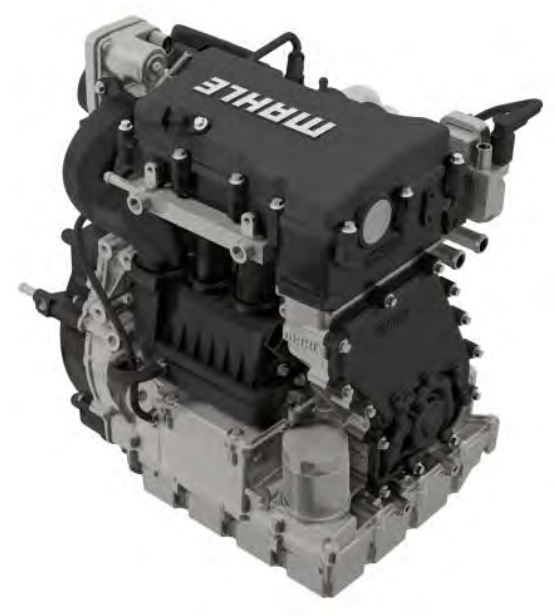

Figure 1: The $30 \mathrm{~kW}$ range extender unit.

This paper presents an overview of the REx unit concept, design and development phases and the demonstrator vehicle specification and construction. It then focusses in greater details into the development of the operating strategy for the REx unit and the steps taken to minimize the fuel consumption and the optimisation of the $\mathrm{NVH}$ characteristics of the vehicle, including the development of a GPS based operating strategy for the REx unit within the demonstrator vehicle.

This paper goes on to examine the range extender power requirements for larger vehicles and will present the design and development activities for developing a highly compact and power dense range extender family which would be applicable to a wide array of light commercial 
and passenger vehicle applications. The paper will go on to describe the resulting engine family and present the initial test results for the upgraded REx unit.

\section{Range Extender Unit}

\subsection{Concept selection}

The REx engine design objectives were set to meet the requirements for a compact-class REEV. A driveline model of an REEV was constructed and the power requirements to maintain battery state of charge were analysed. It was concluded that about $30 \mathrm{~kW}$ of mechanical power ( $\sim 26$ to $27 \mathrm{~kW}$ electrical output) was needed for this application [1]. Once the power requirement had been determined from initial simulations, the most appropriate type of engine to be used for the REx unit was then investigated. A study was conducted to identify potential engine types that would suit such an application. This assessment included conventional reciprocating piston engines of all types (including 2and 4-stroke operating cycles using gasoline and diesel), rotary engines, gas-turbines, plus some more unconventional engine concepts (e.g. free piston and swash-plate engines).

Comparative ranking was employed to quantify the differences between the potential engine concepts using against attribute deemed desirable for a range extender unit. It was ultimately concluded that a 4-stroke, reciprocating piston, gasoline engine was the most suitable engine type for a near-term, mass production feasible solution.

\subsection{Detailed design}

Once the initial decision that the REx engine should be a 4-stroke, reciprocating piston, gasoline engine had been made, the next step was to define the basic engine configuration. Parametric CAD models were built for 2-, 3- and 4-cylinder engines of inline, Vee and flat (Boxer). From an NVH viewpoint it was deemed desirable to keep the operating speed of the range extender engine as low as possible. However, this requirement conflicts with the desire to minimize the size of the engine, as speed reductions reduce the specific output achievable. A maximum operating speed of $4000 \mathrm{rev} / \mathrm{min}$ was selected for achieving the desired $30 \mathrm{~kW}$ output. Additionally, a modest specific output for the engine was selected, with the aim of achieving this without the recourse of a highly tuned inlet or exhaust system, which could lead to an overly large or complex design for these items. A brake mean effective pressure of (BMEP) 10 bar was deemed to be readily achievable based on MAHLE Powertrain's experience, giving rise to a swept volume selection of 0.9 litres.

Key parameters such as total package volume (including a generator), estimated weight and cost were quantified using both CAD data and available empirical data. These estimations were used to rank the concepts relatively, whilst also considering the likely $\mathrm{NVH}$ characteristics. The results from the study clearly highlighted the advantages of the in-line 2-cylinder engine for this application [2]. Once the key architectural parameters for the engine had been selected, a concept design was created and resulted in the final concept engine design specifications as summarized in Table 1. 
Table 1: Specifications of the $30 \mathrm{~kW}$ range extender unit.

\begin{tabular}{|l|l|}
\hline Configuration & In-line, 2-cylinder \\
\hline Operating cycle and fuel & 4-stroke, gasoline \\
\hline Displacement & 0.9 litres \\
\hline Generator & Permanent magnet, axial flux \\
\hline Maximum mechanical power & $30 \mathrm{~kW}$ at $4000 \mathrm{rev} / \mathrm{min}$ \\
\hline Maximum BMEP & 10 bar between 2000 and $4000 \mathrm{rev} / \mathrm{min}$ \\
\hline
\end{tabular}

The overall engine design is targeted at maintaining the lowest production cost to achieve the performance targets within the smallest possible package volume. Given the low rated speed, and moderate specific power output requirements, the engine only requires 2valves per cylinder. Similarly port fuel injection is employed for low cost, good NVH and best start-up emissions. In order to minimize overall package, both the generator and the intake and exhaust systems are integrated into the engine structure and closely packaged respectively.

Removing the need for a balancer shaft was viewed as being fundamental to creating a cranktrain with low series production cost and aids in keeping the engine light and compact. Normally for in-line 2-cylinder engines, one or two balancer shafts would be used to compensate for the residual primary forces and the firing interval of the engine would be evenly spaced, with both cylinders at top-dead center (TDC) together, one firing and the other undergoing gas-exchange. Instead, an uneven firing interval was specifically chosen for this range extender application, whereby one cylinder is at TDC whilst the other is at bottom-dead center (BDC), giving rise to primary vertical balance and a $180^{\circ}-540^{\circ}$ interval between firing events.

\subsection{Performance}

The performance of the REx unit was initially assessed, with the engine coupled to a dynamometer rather than the generator. The measured power, torque and fuel consumption of the engine are shown in figure 2. Peak mechanical power from the engine, of $30 \mathrm{~kW}$, was achieved at $4000 \mathrm{rev} / \mathrm{min}$. It can be seen in figure 3 that the engine achieves an almost constant torque level above the target value set in the desired operating speed range of 2000 to $4000 \mathrm{rev} / \mathrm{min}$.

After the initial break-in and calibration, the unit was tested with the generator in place, disconnected from the dynamometer. The generator has the capability to absorb the torque produced by the engine and is also used to start the engine, meaning that no separate starter motor is required. The control of the generator is managed by an inverter, which is in turn controlled by the engine control unit (ECU). A proprietary flexible ECU (MFE unit) is used, with a control strategy developed specifically for the range extender application. The fuel consumption of the REx unit has been measured, and the total system efficiency map is shown in figure 3. A maximum total system efficiency (includes the effects of the efficiencies of the engine, generator and inverter) of $31 \%$ has been achieved. 


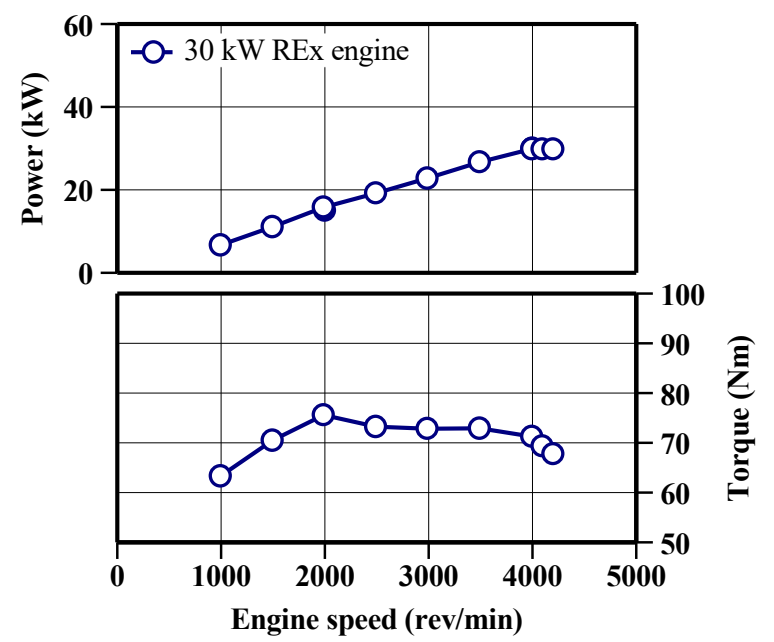

Figure 2: Tests results from the $30 \mathrm{~kW}$ range extender engine.

The REx unit has been designed to be as light, efficient and cost effective as possible. As previously mentioned, normally for in-line 2-cylinder engines, one or two balancer shafts would be used to compensate for the residual primary forces and an even firing interval $\left(360^{\circ}-360^{\circ}\right)$ would be adopted. Instead, a $180^{\circ}-540^{\circ}$ firing interval $\left(360^{\circ}\right.$ and $540^{\circ} \mathrm{TDC}$ angles) was specifically chosen for this range extender application as this solution has no primary out of balance forces. This firing order gives no firing events in the $1^{\text {st }}$ revolution of the engine cycle and two firing events in the $2^{\text {nd }}$ revolution of the cycle.

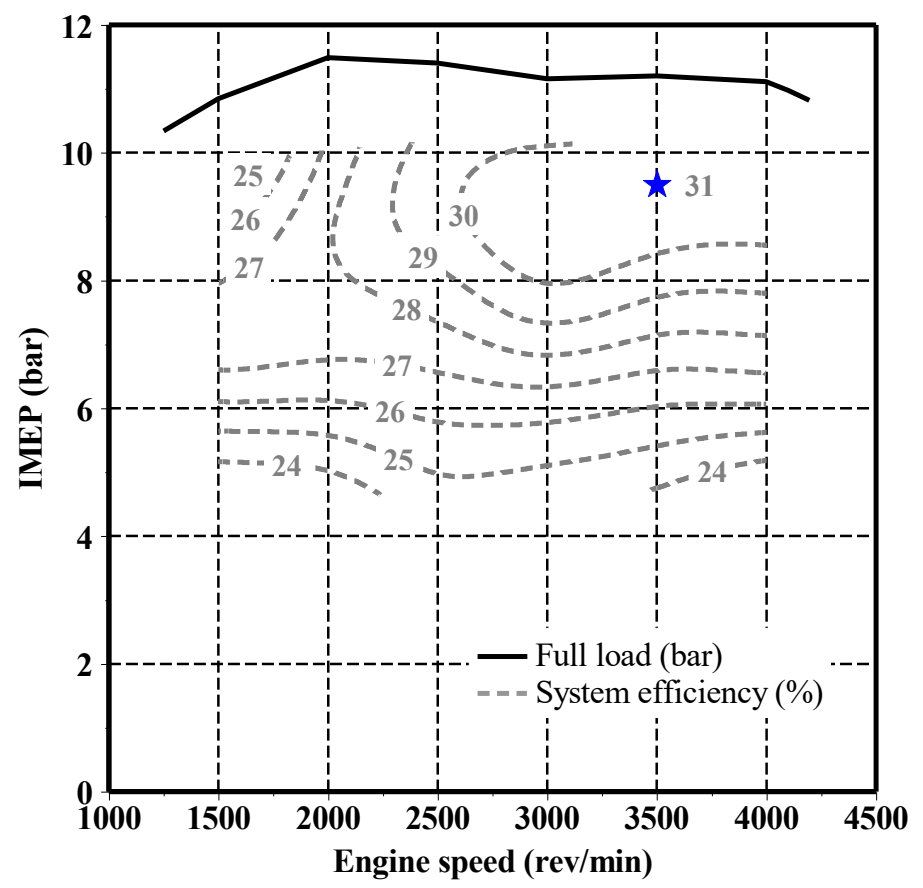

Figure 3: Measured efficiency map for the $30 \mathrm{~kW}$ REx unit.

The very low rotational inertia and uneven torque distribution over the engine cycle gives rise to large speed fluctuations during the cycle. Figure 4a shows measured cyclic speed fluctuations when operating at a cycle average speed of $2000 \mathrm{rev} / \mathrm{min}$ and $80 \%$ load. When a constant torque load is applied to the engine via the generator the engine speed 
can be seen to fluctuate between 2300 and $1560 \mathrm{rev} / \mathrm{min}$ across the cycle, giving a peak to peak speed variation of up to $740 \mathrm{rev} / \mathrm{min}$ per cycle.

A dynamic control strategy for the generator has been devised, where it is switched off during the 1 st revolution of the engine cycle and then activated at twice the mean cyclic torque during the 2 nd revolution, as depicted in figure $4 \mathrm{~b}$. Figure $4 \mathrm{a}$ shows the effect of this dynamic torque control strategy on the engine speed and it can be seen from figure 4a that the cyclic speed variation is almost half of that observed using constant torque generator control. Further testing has demonstrated that the dynamic torque control of the generator yields similar benefits across the entire operating range of the engine. It was found that the peak accelerations observed corresponded to engine firing frequency and it was also found that the dynamic generator control reduced these accelerations by roughly $30 \%[3]$.

a)

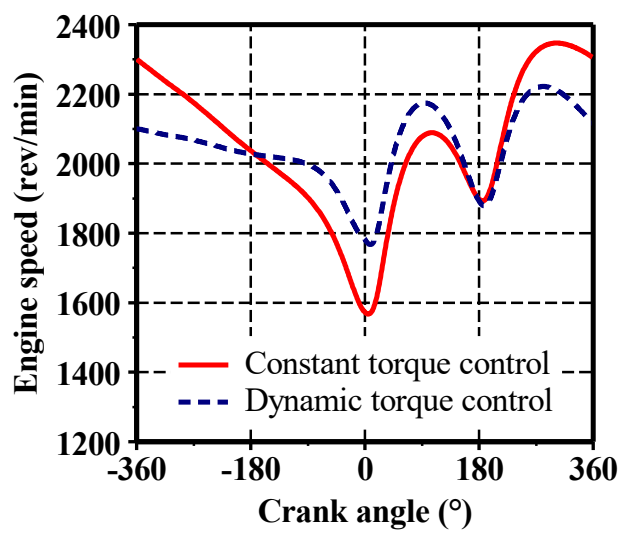

b)

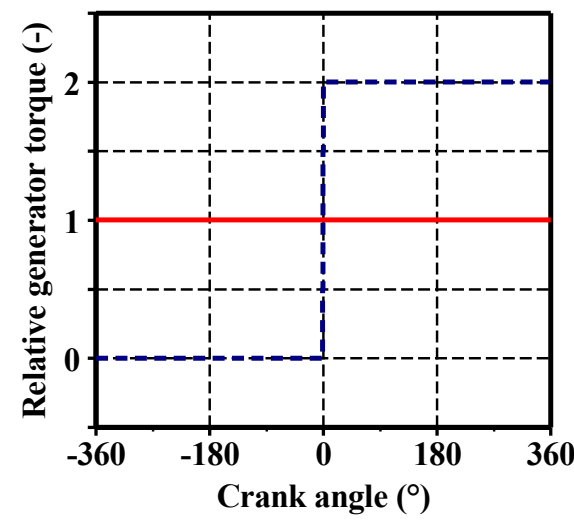

Figure 4: Dynamic generator control strategy (a) Cyclic speed fluctuations; (b) Generator torque switching.

\section{Range Extended Electric Vehicle Demonstrator}

In order to enable development and refinement of the REx system, it has been installed into a vehicle. A current production vehicle has been fitted with an electric drive-line and the range extender engine. The REEV specification has been developed with the target of meeting the performance of the conventional baseline vehicle.

\subsection{Demonstrator vehicle}

To demonstrate the compactness of the $30 \mathrm{~kW}$ REx unit, a small car was used as the basis for the demonstrator. An Audi A1 was selected for the conversion, shown in figure 5. The performance targets set for the demonstrator vehicle were aimed towards matching the dynamic performance of the base vehicle and included a $0-100 \mathrm{~km} / \mathrm{h}$ time of less than 12 seconds. Other targets included a pure EV range of over $60 \mathrm{~km}$ and a charge sustaining speed of $120 \mathrm{~km} / \mathrm{h}$. In combination with a package study, the performance targets set enabled suitable electric driveline components to be selected and sourced for the REEV demonstrator.

To meet the pure EV range target a $14 \mathrm{kWh}$ Li-ion battery pack was selected, operating at a nominal voltage of $350 \mathrm{~V}$, and this has been installed beneath the boot floor in the demonstrator vehicle. The grade-ability, acceleration and maximum speed targets, a 
traction motor with a peak power of $100 \mathrm{~kW}$, and continuous power output of $64 \mathrm{~kW}$, has been used.

a)

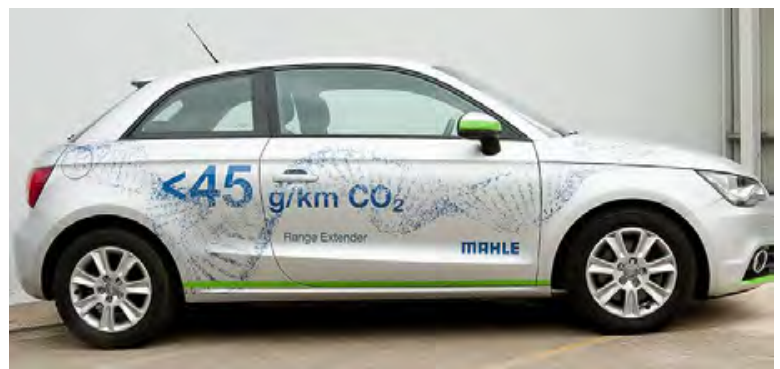

b)

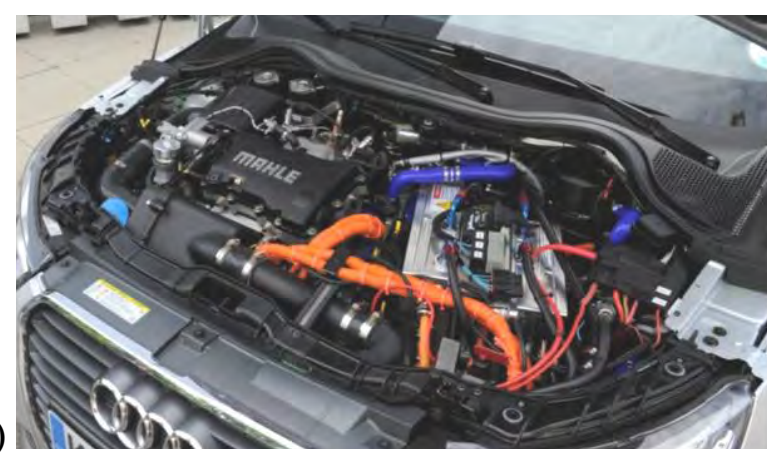

Figure 5: The REEV demonstrator; a) Vehicle exterior; b) Under bonnet.

\subsection{Cooling system}

PHEVs, including REEVs, require an electrical storage device (battery) and at-least one electric motor and associated motor controller, as well as a conventional internal combustion (IC) engine. To achieve high power densities the battery, motors and associated controllers are typically liquid cooled. The internal combustion engine is also usually also liquid cooled, with the coolant maintained at around $90{ }^{\circ} \mathrm{C}$ during operation for efficient combustion and reduced heat transfer. In some cases the engine/transmission lubrication systems need to be cooled as well and typically have a temperature range compatible with the engine coolant circuit.

The Li-Ion battery used in the REEV demonstrator needed to be maintained at a temperature between $0{ }^{\circ} \mathrm{C}$ and $40{ }^{\circ} \mathrm{C}$. Thus, the battery pack will need heating in cold ambient conditions and, in hot climates, will also need cooling below the ambient air temperature. This necessitates the capability to heat and sub-cool the battery coolant, as discussed in detail by Neumeister [4]. The traction motor can withstand temperatures of $120{ }^{\circ} \mathrm{C}$ or higher, but the power electronics has a coolant inlet temperature limit of in the range of 65 to $90{ }^{\circ} \mathrm{C}$. The differing temperature requirements and limits for these components lead to requirements for separate cooling systems, in addition to the cooling system required to achieve cabin air heating, cooling and dehumidification. Potentially, for a typical electric hybrid vehicle, as many as five discrete coolant circuits may be required, with their associated pumps, heat exchangers, cooling fans and control valves. Opportunities exist for combining circuits for series applications for cost, weight and efficiency savings. To be able to combine cooling circuits, they must have complimentary 
heat rejection, similar fluid operating temperatures and be able to operate with the same cooling medium.

The resulting cooling system layout is shown schematically in figure 6 . The aim of the layout shown in figure 6 is to maximize the conditions under which the REEV could be used in both hot and cold climates. In this layout, the high temperature (engine) circuit is kept stand-alone due to the unique characteristics of the temperature profile. The medium temperature components (traction motor, REx generator and power electronics) are integrated into one circuit. If the pressure drops of the electrical components are high (as is often the case), then it will be necessary to use a high pressure ratio EWP. Typically, required flow rates are low (in the region of 5-10 1/min) but multiple components arranged in series create a very high restriction for the coolant pump.

An electric air conditioning (A/C) compressor is used for the cabin cooling, but is teamed with a chiller unit to allow battery sub-cooling (cooling to sub-ambient conditions). The $\mathrm{A} / \mathrm{C}$ and battery cooling circuits can utilize the same radiator to reject heat from both systems to the environment [5]. To facilitate this, an iCond unit, also shown in figure 6, is employed to transfer heat between the $\mathrm{A} / \mathrm{C}$ refrigerant and the coolant in the low temperature circuit. The iCond is an expansion of the conventional $\mathrm{A} / \mathrm{C}$-system, which enables the deletion of the direct condenser unit in the cooling module, thus saving package space at the front of the vehicle. This in turn prevents compromises in exterior styling, crash behavior, as well as the additional weight and cost of the of the condenser radiator. With the iCond unit it is possible to pass the waste heat from the refrigerant circuit into the battery cooling circuit, as shown in figure 6 , because the temperatures are similar. The two circuits also have opposite temperature profiles; the main load on the $\mathrm{A} / \mathrm{C}$ side is during initial pull down and under these circumstances the vehicle is normally stationary or moving at slow speed, so the heat rejected by the $\mathrm{A} / \mathrm{C}$ is much higher than the battery. When the battery is in heavy use, the $\mathrm{A} / \mathrm{C}$ is normally in sustaining mode and only extracting a small amount of heat from the system. In the extreme case, where a heat-soaked vehicle is instantly driven onto the high-way, then battery requirements would take precedent and passenger comfort may be briefly compromised. However, this is likely to be for a very short period, as results presented later indicate that such a system is able to drop the battery coolant temperature rapidly.

An electric water heater is used for cabin heating and is operated when cabin heating is required and insufficient waste heat is available from the combustion engine. The same heater is also used in conjunction with a separate heat exchanger and valve system to heat the battery coolant when necessary. An electric heater is used instead of a combustion heater, despite the lower system efficiency, to avoid the issue of automatically running the heater and producing combustion emissions in non-ventilated areas such as a garage or indoor parking structure.

This system should enable the cooling of all system components under hot conditions, using the sub-cooling for the battery when required. Heating of the battery is also possible and can be achieved as a pre-conditioning process with the required control system deployed. The downside of such a system is the level of complexity of the components and control system required, especially with the addition of the battery heating and cooling loops. However, it is clear that both functions are necessary for 
uncompromised function of these types of vehicles, even in normal operating environments.

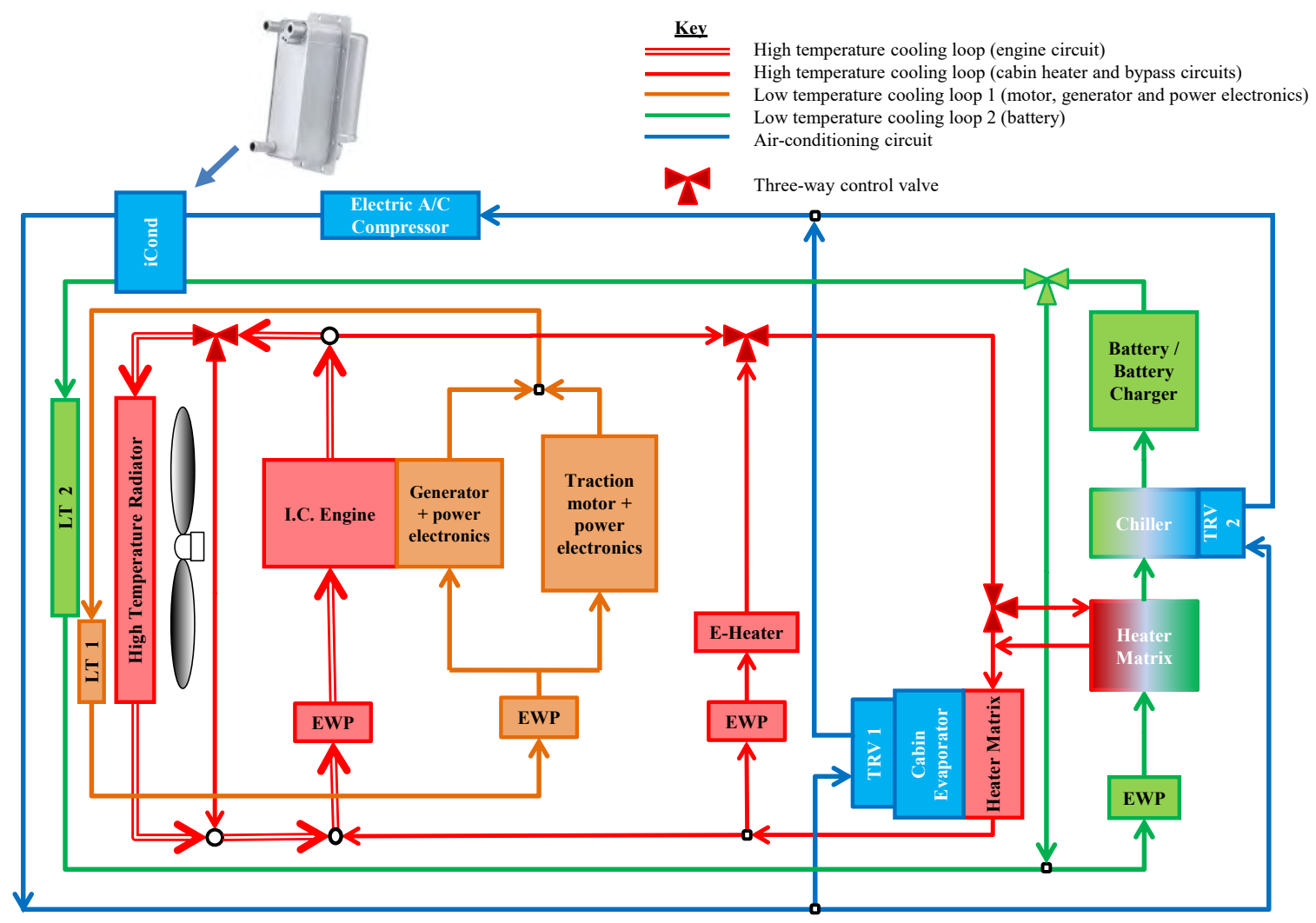

Figure 6 : REEV demonstrator vehicle cooling system layout and iCond unit.

\subsection{Operating strategy}

The baseline operating strategy of the range extender engine has been devised to maximize the fuel economy of the vehicle, whilst maintaining an acceptable NVH characteristic. Additionally, the operation of the engine kept within is maintained in a region of the operating map where the intra-cyclic speed fluctuations are minimized to ease the burden on the engine management system and enable repeatable control characteristics, as well as reducing engine cyclic vibrations.

The REx unit power request is calculated to meet the tractive power demand of the vehicle, based on current speed, with an additional percentage added to allow for hotel loads and vehicle transient power requirements (e.g. hard acceleration events). This road load curve is shown in figure 7, along with the range extender engine power and engine speed operating lines. The engine operating strategy adopted varies REx engine speed as a function of the vehicle speed. The reactive control strategy adopted for the range extender engine, based on battery state of charge (SOC) and vehicle speed, means that the engine does not generally run below a vehicle speed of $20 \mathrm{~km} / \mathrm{h}$, unless the battery SOC has become critically low. This is primarily for NVH purposes, as the engine operation may become intrusive compared to the near silent electric vehicle operation. Using this strategy the operation of the REx unit is virtually imperceptible to the vehicle occupants, as any noise or vibration due to the engine is masked by road and wind noise. This strategy has been adopted to give the best tail-pipe $\mathrm{CO}_{2}$ figure for the vehicle. Vehicle 
testing has yielded an electric only range of $67 \mathrm{~km}$, and a weighted $\mathrm{CO}_{2}$ figure of $42 \mathrm{~g} / \mathrm{km}$ for the NEDC cycle [3].

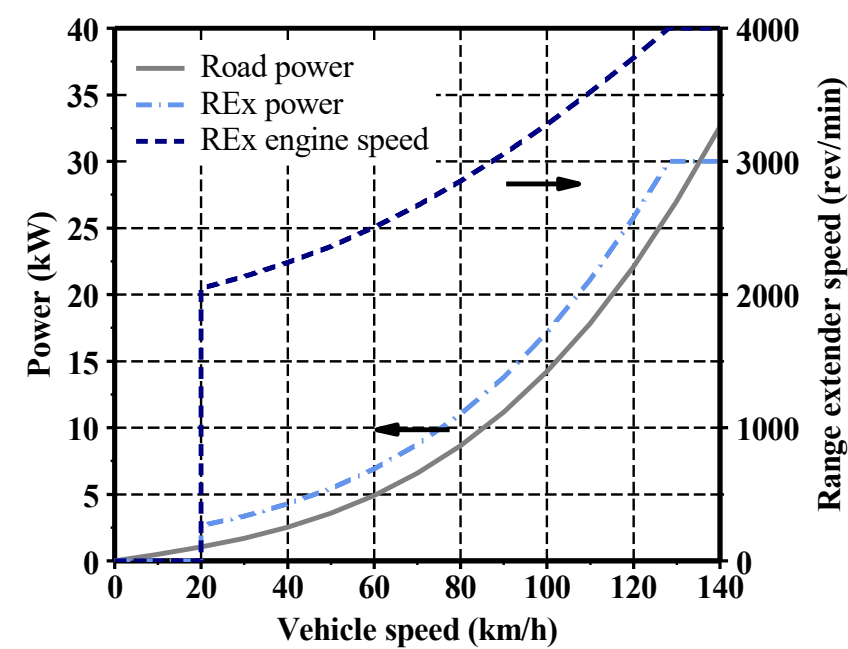

Figure 7: Road load power requirement and proposed Rex unit operation.

\section{GPS based control strategy}

The REEV demonstrator was originally developed with a purely reactionary control strategy. Once the battery SOC is depleted the REx is activated to provide the energy required to propel the vehicle. As part of the continuing development of this vehicle, it has been developed a control software which can intelligently manage the use of the battery energy through the combined use of global positioning system (GPS) and road topographical data. Advanced knowledge of the route prior to the start of a journey enables the software to calculate the SOC throughout the journey and pre-determine the optimum operating strategy for the range extender to enable best charging efficiency and minimize $\mathrm{NVH}$.

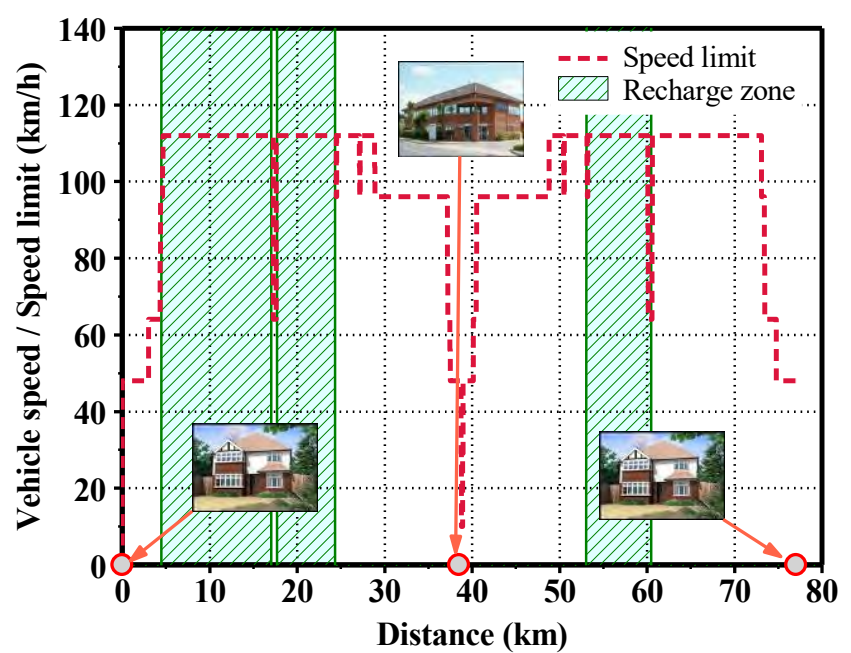

Figure 8: REx operation strategy selected by the GPS based controller at trip outset.

The software can also operate without a pre-determined route being selected. In this case the software will interrogate a database of previous drive data and select the most likely route being driven. Based on the predicted route the software will then select a suitable charging strategy for best efficiency. The system considers an array of factors to determine the 
optimum charging strategy such as the driving style of the driver. It is capable of improving upon its own predictions of vehicle energy usage over a series of journeys and aims to produce the most efficient charging strategy. The software allows the vehicle to operate 100 $\%$ electrically in congestion charging zones, by pre-emptively charging the battery prior to entry.

For the GPS based control strategy the speed limit profile is used to predetermine the REx operating points during the route. Figure 8 shows the regions of the journey that are preselected for REx operation. The selected regions correspond to reasonably long periods of high vehicle speed, enabling high-power and efficient REx operation. The strategy will preferentially select the earliest opportunities to operate the REx unit, this enables the vehicle to be in the best position to accommodate unforeseen changes to the route, or periods where it may not be desirable to operate the REx unit, i.e. in traffic queues where the vehicle speed may be significantly lower than anticipated.

Figure 9 shows an example of a comparison between the battery SOC history for the baseline strategy and the GPS based control strategy over the same route. It can be seen that the battery SOC for the GPS based strategy remains higher for a greater proportion of the journey than that of the baseline strategy. The open-circuit voltage of the battery pack is higher with higher a SOC, thus at any charge, or discharge, power the required current is marginally lower, which in turn leads to a slight reduction in the electrical losses in the system. For trip analysed, the GPS based controller gives an actual fuel consumption reduction of over $5 \%$.

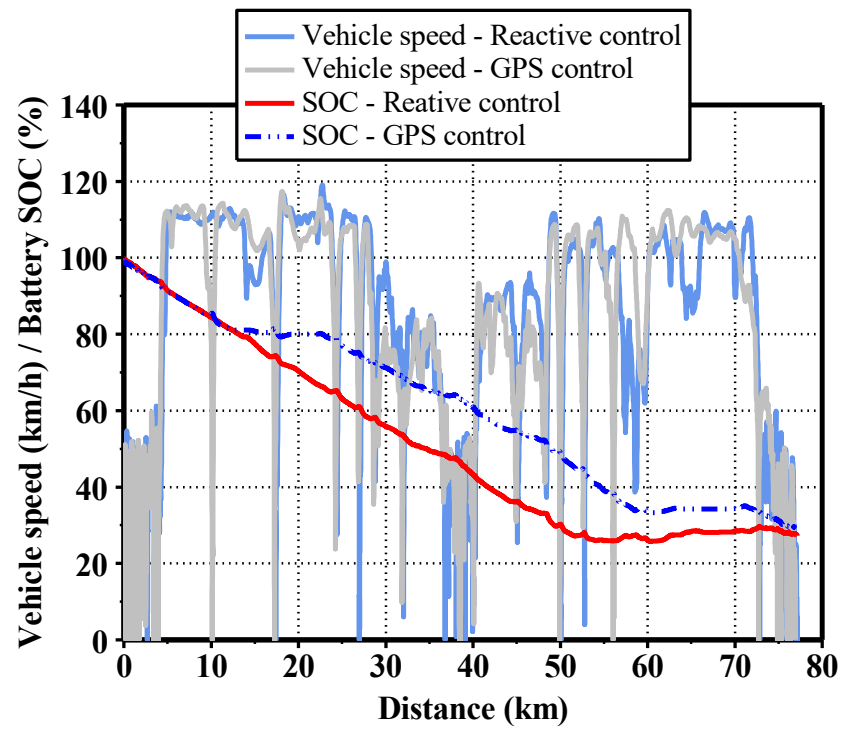

Figure 9: Comparison of SOC history for baseline and GPS based control strategies over the same route.

\section{Range extender family concept}

To widen the range of vehicles that the REx unit could be suitable for, methods have been investigated to increase the power output of the unit with minimal modifications. Initially, the power requirements for a range of potential target vehicles have been analysed. From a study undertaken previously [1], it was apparent that the key factors for determining the power requirement for a REx unit, for a given REEV application, is the power required to propel the 
vehicle during any prolonged periods. The salient conditions to consider are the power requirements for continuous high-speed cruising or prolonged hill-climbing.

The REx power requirements for a number of vehicle classes have been analysed using these simplified assessment criteria using published dynamometer coefficients from the EPA [6] to estimate the road load characteristics of a number of differing vehicles from a variety of segments. Figure 10 shows the resulting suggested range extender power break points for the REx family:

- The $30 \mathrm{~kW}$ REx unit that has already been developed is suitable for REEVs up to a curb weight of up to $1600 \mathrm{~kg}$.

- It is suggested that a $40 \mathrm{~kW}$ REx unit would be suitable for vehicles between $1400 \mathrm{~kg}$ and $2100 \mathrm{~kg}$.

- Finally, a $50 \mathrm{~kW}$ REx unit would be suitable for REEVs with a curb weight from about $1900 \mathrm{~kg}$ up to $2700 \mathrm{~kg}$. This unit could also be used for lighter vehicles with charge sustaining targets set at higher vehicle speeds, or light commercial vehicles with lower vehicle speed requirements.

With these three power levels it is possible to seamlessly serve REEVs with curb weights from $<1000 \mathrm{~kg}$ up to $2700 \mathrm{~kg}$ enabling virtually all passenger car applications to be accommodated and also being suitable for many light commercial applications with a single base engine architecture.

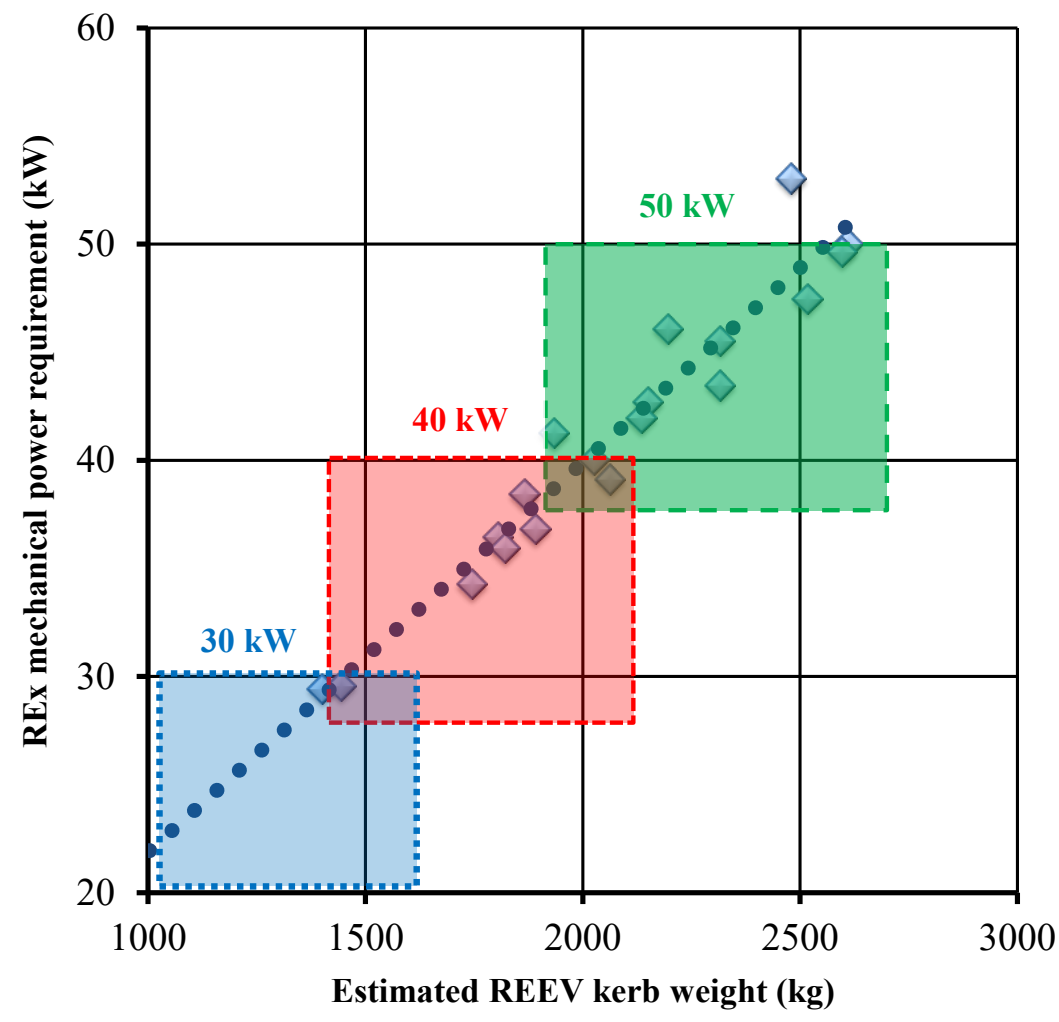

Figure 10: Range extender family power steps.

Ideally, the REx family of power outputs can be achieved whilst sharing major components with the original $30 \mathrm{~kW}$ REx engine shown in figure 1 . The original REx engine achieves 30 
$\mathrm{kW}$ mechanical power at an engine speed of $4000 \mathrm{rev} / \mathrm{min}$. As discussed, the maximum power speed of the engine was set at this relatively low level to reduce the $\mathrm{NVH}$ of the engine to a level that would be completely unobtrusive to the occupants. Experience with the REx demonstrator vehicle has indicated that higher engine speeds could be accommodated without compromising the NVH of the vehicle unduly, but careful consideration must be given to the durability of the resulting unit. The crankshaft, connecting rod, camshaft profile and intake manifold have been redesigned to enable to the engine to achieve $40 \mathrm{~kW}$ mechanical power at $5500 \mathrm{rev} / \mathrm{min}$. This has been demonstrated on the testbed and the test results are shown in figure 11, but the in-vehicle NVH remains untested.

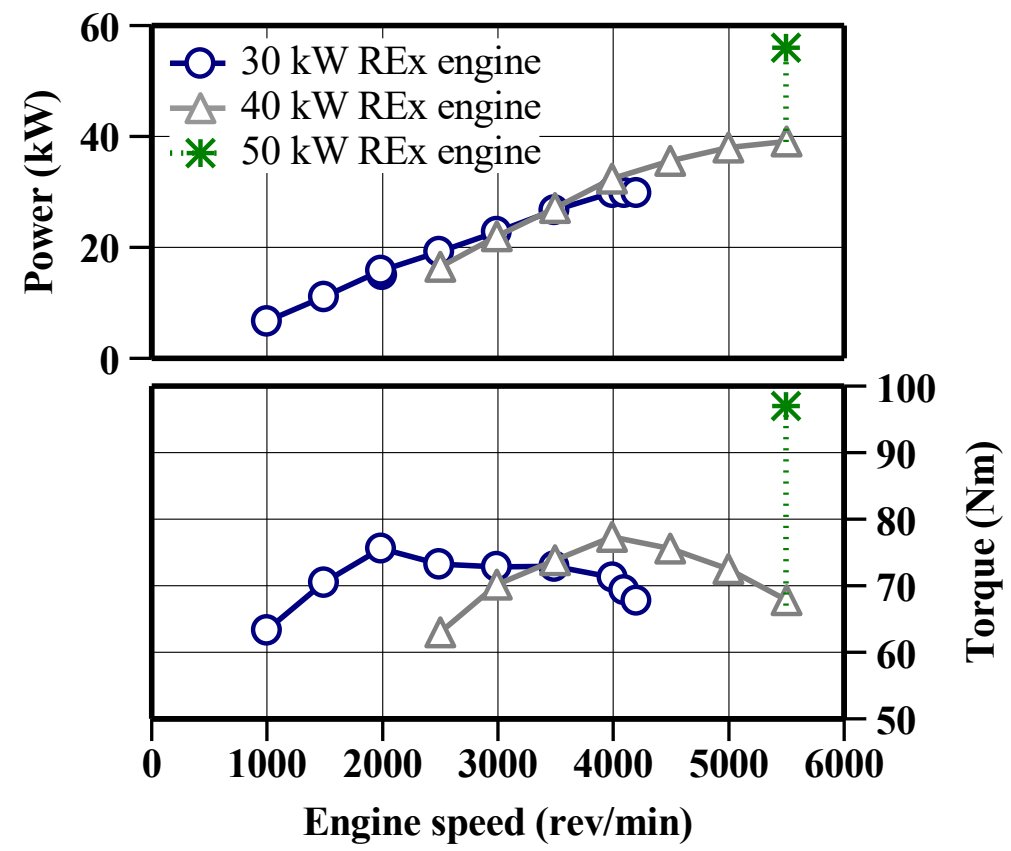

Figure 11: Test results for the 2-cylinder versions of the REx family.

Increasing the engine displacement, with increased bore and stroke or by additional cylinders, necessitates the design of a completely new engine and will increase the package size and weight of the unit. A three cylinder version of the engine, based on the same cylinder set as the original engine, has been developed in CAD, and is shown in figure 12a. The resulting unit is $92 \mathrm{~mm}$ longer than the baseline engine and simulations indicate that it will achieve $45 \mathrm{~kW}$ mechanical power at $4000 \mathrm{rev} / \mathrm{min}$.

Pressure charging the unit is an attractive option, as it enables the target power to be achieved at a low engine speed, without the requirement to increase displacement. Exhaust gas turbocharging could be problematic as the exhaust flow is highly pulsatile due to the low cylinder count and uneven firing order. A mechanical supercharger is possible for future developments of the engine, but would require a redesign of the front end cam chain drive to enable mechanical drive power to be accommodated. An electrically powered supercharger (eSupercharger) is well suited to this application as it provides a method of providing boosted air to the engine without the need for any mechanical drive, thus minimizing the required changes to the base engine architecture. The engine already has a high voltage electrical system available, from which the eSupercharger can be readily driven, potentially presenting a cost effective and efficient solution. The engine has been tested with an Aeristech eSupercharger [7], and is shown in figure $12 \mathrm{~b}$, to validate the capability of the base engine 
under pressure charged operation and achieved $56 \mathrm{~kW}$ mechanical power at $5500 \mathrm{rev} / \mathrm{min}$, as shown in figure 11. The eSupercharger required $4.5 \mathrm{~kW}$ electrical power at this operating point, so the net mechanical power achieved is still in excess of $50 \mathrm{~kW}$.

a)

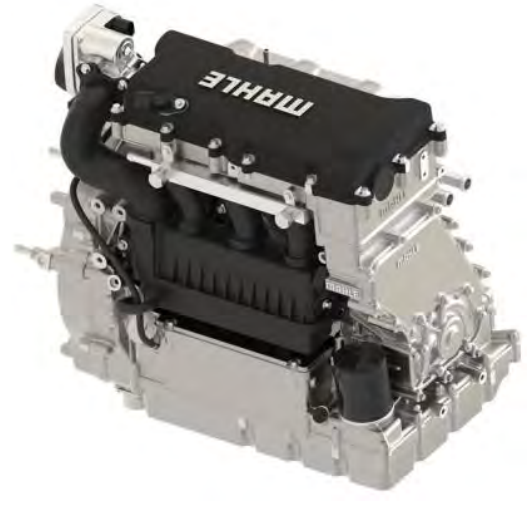

b)

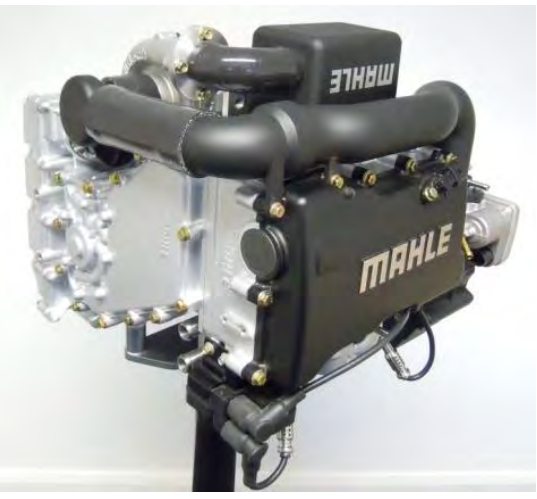

Figure 12: Potential REx family; a) 3-cylinder naturally aspirated; b) eSupercharged 2cylinder.

\section{CONCLUSION}

A 0.9 litre, $30 \mathrm{~kW}$, dedicated REx unit has been developed to meet the requirements for a compact-class REEV. A demonstrator vehicle has been developed and has successfully validated the performance and NVH characteristics of the unit.

Control software to manage the use of the battery energy, through the combined use of GPS and road topographical data, has been developed. Advanced knowledge of the route prior to the start of a journey enables the software to predict the battery SOC throughout the journey and pre-determine the optimum operating strategy for the range extender to enable best charging efficiency and minimize NVH.

To broaden the scope of the applicability of the REx unit methods have been investigated to increase the power output of the unit with minimal modifications. Based on analysis of the power required for REEVs of differing vehicle curb weights, it has been concluded that the addition of 40 and $50 \mathrm{~kW}$ versions would enable the REx family to accommodate the requirements of a range of REEV curb weights from $<1000 \mathrm{~kg}$ to over $2500 \mathrm{~kg}$. The engine has been adapted to operate at a higher speed to achieve $40 \mathrm{~kW}$ mechanical power and also tested with an eSupercharger and achieved in excess of $50 \mathrm{~kW}$ mechanical power. The addition of an extra cylinder has also been investigated.

\section{REFERENCES}

[1] BASSETT, Michael; FRASER, Neil; BROOKS, Thomas; TAYLOR, Greg; HALL. Jonathan; THATCHER; Ian A Study of Fuel Converter Requirements for an Extended Range Electric Vehicle, SAE Congress Paper No. 2010-01-0832, Detroit, 2010. 
[2] BASSETT, Michael; THATCHER, Ian; BISORDI, Andre; HALL, Jonathan; FRASER, Neil; WARTH, Marco Design of a Dedicated Range Extender Engine, SAE Congress Paper No. 2011-01-0862, Detroit, 2011.

[3] BASSETT, Michael; Hall, Jonathan; WARTH, Marco Development of a Dedicated Range Extender Unit and Demonstration Vehicle, Barcelona, Spain, EVS27, November 17-20, 2013.

[4] NEUMEISTER, Dirk System Efficiency of the Thermal Battery Management, 5th International Congress Li Ion Batteries, April 2012.

[5] EILEMANN, Andreas; DIEM, Johannes; HOFMANN, Herman, From indirect Charge Air Cooling to a 2-layer Cooling Module: Assumptions, Preconditions and Perspectives, 4th European Workshop on Mobile Air Conditioning and Vehicle Thermal Systems, Turin, December 2011.

[6] EPA dynamometer coefficients for vehicle type approval tests Accessed on:

https://www.epa.gov/compliance-and-fuel-economy-data/annual-certification-test-datavehicles-and-engines Accessed on: $4^{\text {th }}$ May 2018.

[7] Aeristech eSupercharger datasheet, Aeristech Ltd., http://aeristech.co.uk/wpcontent/uploads/case_study_esupercharger_for_rex_engine_v22.pdf Accessed on: $4^{\text {th }}$ May 2018 . 